\title{
Water-Polymer Perturbation Characterization and Rules of Polymer Flooding in Offshore Heavy Oilfield
}

\author{
Yuyang Liu $\mathbb{D}^{1,2}$ Xiaodong Kang, ${ }^{1,2}$ Zhijie Wei $\mathbb{D}^{1,2}$ Xudong Wang, ${ }^{1,2}$ and Zhen Zhang ${ }^{3}$ \\ ${ }^{1}$ State Key Laboratory of Offshore Oil Exploitation, Beijing 100028, China \\ ${ }^{2}$ CNOOC Research Institute Co. Ltd, Beijing 100028, China \\ ${ }^{3}$ CNOOC Energy Development Co. Ltd, Tianjin 300451, China
}

Correspondence should be addressed to Yuyang Liu; liuyy52@cnooc.com.cn

Received 24 November 2020; Revised 25 February 2021; Accepted 5 March 2021; Published 22 March 2021

Academic Editor: Xiang Rao

Copyright @ 2021 Yuyang Liu et al. This is an open access article distributed under the Creative Commons Attribution License, which permits unrestricted use, distribution, and reproduction in any medium, provided the original work is properly cited.

Water injectors and polymer injectors coexist after well pattern infilling in some offshore oilfields, which exerts a deep impact on oil exploitation. In order to quantitatively characterize the injected water-polymer perturbation degree and analyze perturbation laws, water-polymer perturbation coefficient is proposed and established by comparing the displacement process of water-polymer coflooding and pure polymer flooding, which quantifies the dynamic change of displacement volume of injected water and polymer, and controlling strategy is discussed correspondingly to improve the development effect of water-polymer coflooding. Finally, a field case is used to demonstrate this new evaluation method. The results show that water-polymer perturbation coefficient has a good correlation with oil increasing, and water-polymer coflooding process can be divided into five stages according polymer perturbation coefficient. In addition, water-polymer coflooding has a better oil increasing effect than pure polymer flooding at the initial stage, but for a long period, development effect of pure polymer flooding is much better. The result has a great significance to quantitatively characterize water-polymer perturbation degree and make adjustment measurements.

\section{Introduction}

The oilfields in Bohai Bay are characterized by high oil viscosity, multilayer, unconsolidated, and strong heterogeneity. After long time of water injection or polymer injection, dominant seepage channels are easy to appear, which lead to the rapid rise of water cut in producers $[1,2]$. So adjustment of interlayer injection to achieve a balanced displacement is the key to increase recovery. As a mature technology, polymer flooding has been widely used in onshore oilfield with the main purpose to increase water viscosity, such as Daqing and Shengli Oilfield, which has achieved remarkable development effect [3-5]. Compared with the onshore oilfields, the offshore oilfields are companied with more complex implementation conditions, such as high oil viscosity, large well spacing, and limited platform space. Since 2003, polymer flooding has been gradually applied in three Bohai oilfields with the viscosity ranging from 17 to $70 \mathrm{mPa} \cdot \mathrm{s}$ and achieved expected oil increasing effect [6-8]. To better utilize the remaining oil, well pattern infilling was conducted and the new infill wells injected water instead of polymer in order to maintain injection capacity, which led to the polymer injectors and water injectors coexisting. However, the development did not achieve the expected effect.

At present, researches related to water-polymer coflooding mainly focus on the influence on oil production. Numerical simulation method is commonly adopted to investigate the influence of water-polymer coflooding, and it is found that water-polymer coflooding after well pattern infilling will exert an interference and result in poor oil production [9-14]. Laboratory experiments are conducted to analyze the water-polymer contact zone and saturation distribution, and results show that the pressure imbalance in water and polymer injection area will lead to premature water breakthrough [15-17]. In general, lots of research work has been carried out on waterpolymer coflooding, and they hold the similar opinion that 
water-polymer coflooding has a negative impact on oil production. However, previous studies mainly focus on the result rather than the process analysis, and evaluation is not quantitative.

In this paper, we firstly analyzed and compared the displacement characteristics of water-polymer coflooding and pure polymer flooding and proposed a new evaluation method to quantitatively characterize the process of waterpolymer coflooding. Then, based on the reservoir properties and production data of JZ oilfield, a mechanism model is constructed to investigate the change laws of water-polymer perturbation coefficient and analyze the production characteristics of pure polymer flooding and water-polymer coflooding, and controlling strategy is discussed correspondingly. Finally, a field case is used to demonstrate this new evaluation method.

\section{Establishment of Water-Polymer Perturbation Characterization Method}

2.1. Analysis of Water-Polymer Displacement Process. Figure 1 shows the schematic distribution of injected fluid under pure polymer flooding and water-polymer coflooding in single-layer reservoir with uniform thickness in different stages, in which injection rate of water injector is higher than that of polymer. At stage one, both wells are water injectors, and water cut rises from 0 to $80 \%$. At stage two, two development modes are illustrated, Figure 1(a) represents that both two water injectors turn into polymer injectors, and Figure 1(b) represents that one water injector turns into polymer injector. Under equal liquid production rate, the injected water will incline to the polymer injection area, as shown in Figure 1(b), thus compressing the polymer displacement area and displaying a certain "overlap effect" on the front edge of injected polymer solution.

Before the breakthrough of injected water at producers, the overall displacement volume of water-polymer coflooding is larger than that of pure polymer flooding at the same time. After the breakthrough of injection fluid, the displacement volume of injected water and polymer presents a dynamic change, which reflects the perturbation process of injected water and polymer.

2.2. Establishment of Characterization Method. As shown in Figure 1, A and B indicate the displacement area of injected polymer and injected water in water-polymer coflooding, respectively, and A' indicates the half displacement area of injected polymer in pure polymer flooding. Compared with pure polymer flooding, the number of polymer injectors in water-polymer coflooding process reduces from two to one, and the decrease of polymer flooding displacement volume is defined as negative effect; the number of water injector increases from zero to one, and the increase of water flooding displacement area is defined as positive effect.

Considering the positive and negative effects mentioned above, water-polymer perturbation coefficient $\tau$ is proposed to quantitatively characterize the perturbation degree.
Positive effect: the displacement volume of injected water increases, and the interval increase is written as follows:

$$
\Delta \sum D_{w}=\Delta B \times d
$$

Negative effect: the displacement volume of injected polymer decreases, and the interval decrease is written as follows:

$$
\Delta \sum D_{p}=\left(2 \Delta A^{\prime}-\Delta A\right) \times d
$$

Combining Eqs. (1) and (2) and considering the interval polymer dosage injected, water-polymer perturbation coefficient $\tau$ is obtained.

$$
\tau=\frac{\Delta B-\left(2 \Delta A^{\prime}-\Delta A\right)}{\Delta \sum m_{P}} \times d=\frac{\Delta \sum D_{w}-\Delta \sum D_{p}}{\Delta \sum m_{P}} .
$$

Considering the interval production characteristics, cumulative water-polymer perturbation coefficient $\tau_{c}$ is given below.

$$
\tau_{c}=\sum \tau
$$

By analyzing the positive effect brought by the increase of injected water displacement volume and the negative effect brought by the decrease of injected polymer displacement volume, the water-polymer perturbation coefficient can reflect the dynamic change of displacement volume of injected water and polymer at different time and quantitatively characterize the water-polymer perturbation degree.

\section{Water-Polymer Perturbation Laws and Production Characteristics}

3.1. Model Description. In order to further compare the difference between water-polymer coflooding and pure polymer flooding and to analyze the water-polymer perturbation laws, a two-layer numerical simulation model with two injectors and three producers is constructed based on Eclipse, as shown in Figure 2. Parameters are set based on the reservoir properties and production data of JZ oilfield in Bohai Bay. Main input parameters are shown in Table 1. The tracer model is used to intuitively observe the streamline advancing process in waterpolymer coflooding and analyze the interaction between the injected water and polymer.

3.2. Perturbation Laws and Production Characteristics. To investigate the water-polymer perturbation, the simulation process is divided into three stages, and three schemes are set up, as shown in Figure 3.

3.2.1. Perturbation Laws. Figures $4-6$ show the tracer concentration distribution of injected fluid in high- and lowpermeability layers at three times under different injection schemes, and it can be seen in Figure 4 that in pure water flooding, the displacement front of high-permeability layer 


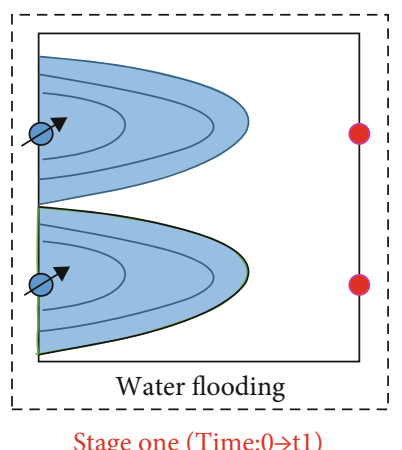

Stage one (Time: $0 \rightarrow \mathrm{t} 1$ )

Polymer injector

Water injector

Producer

Figure 1: Schematic distribution of injected fluid.

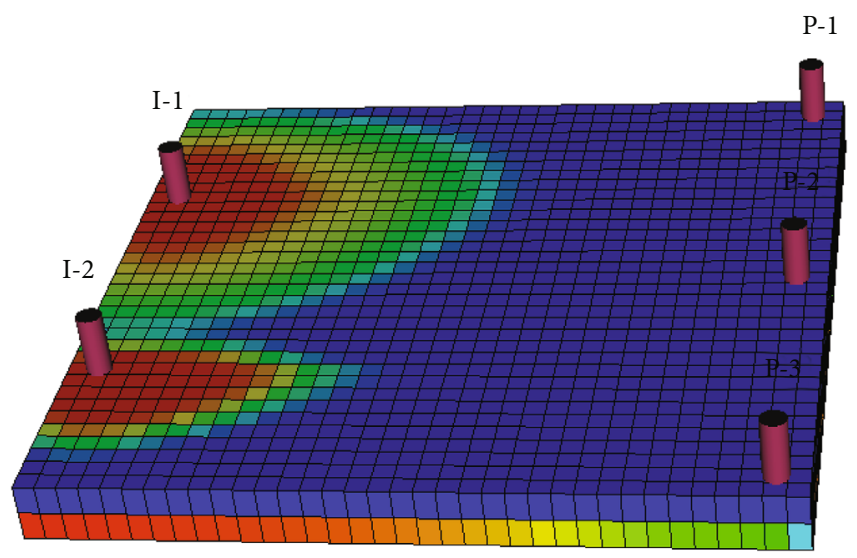

IW1F

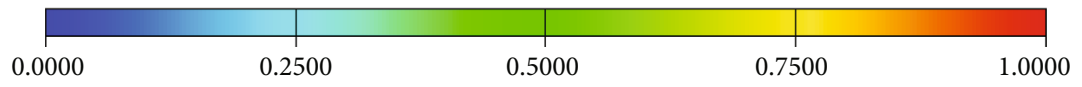

FIgURE 2: Numerical simulation model.

TABle 1: Parameters in the model.

\begin{tabular}{lccc}
\hline Parameters & Value & Parameters & Value \\
\hline Initial reservoir pressure $(\mathrm{MPa})$ & 15 & Formation porosity, fraction & 0.30 \\
Layer with high permeability $(\mathrm{mD})$ & 3000 & Layer with low permeability $(\mathrm{mD})$ & 500 \\
Formation thickness $(\mathrm{m})$ & 10 & Maximum apparent adsorption $(\mathrm{mg} / \mathrm{g})$ & 0.205 \\
Formation temperature $\left({ }^{\circ} \mathrm{C}\right)$ & 65 & Polymer concentration $(\mathrm{mg} / \mathrm{L})$ & 1250 \\
Oil viscosity $(\mathrm{mPa} \cdot \mathrm{s})$ & 17 & Polymer viscosity $(\mathrm{mPa} \cdot \mathrm{s})$ & 13.8 \\
Inaccessible pore volume $(\mathrm{PV})$ & 0.3 & Residual resistance factor & 3.0 \\
Brine water viscosity $(\mathrm{mPa} \cdot \mathrm{s})$ & 1.0 & Average production rate $\left(\mathrm{m}^{3} / \mathrm{d}\right)$ & 78 \\
Water injection rate $\left(\mathrm{m}^{3} / \mathrm{d}\right)$ & 120 & Polymer injection rate $\left(\mathrm{m}^{3} / \mathrm{d}\right)$ & 96 \\
\hline
\end{tabular}

is symmetrical and advances quickly, and the lowpermeability layer has low-producing degree; for pure polymer flooding case as shown in Figure 5, the displacement front of both layer is symmetrical and advances much slower in high-permeability layer compared with pure water flooding, and the low-permeability layer manifests better producing degree; in the case of water-polymer coflooding, injected polymer solution improves the 


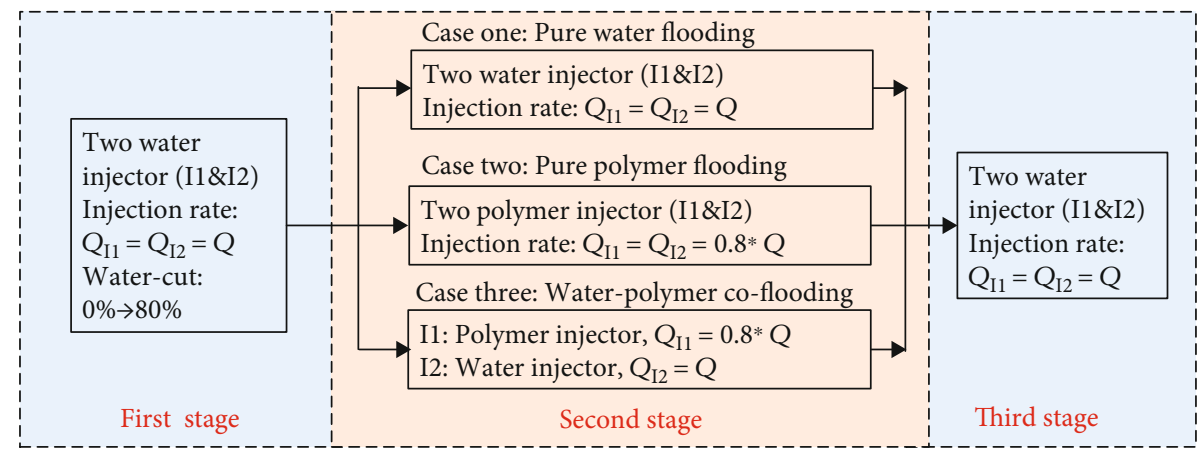

Figure 3: Stage division and simulation schemes.

I1

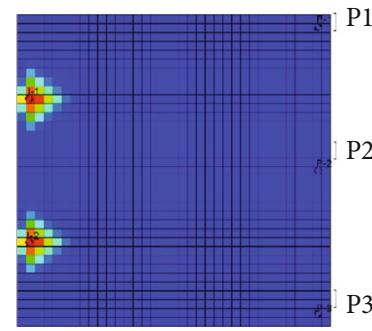

$T=\mathrm{t} 1$

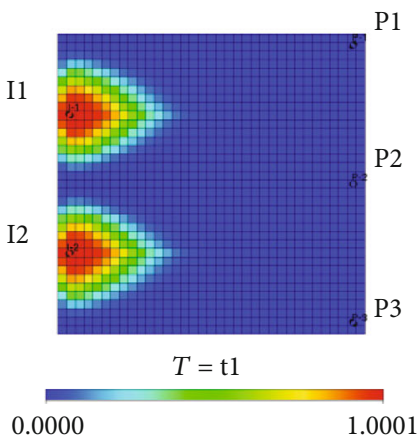

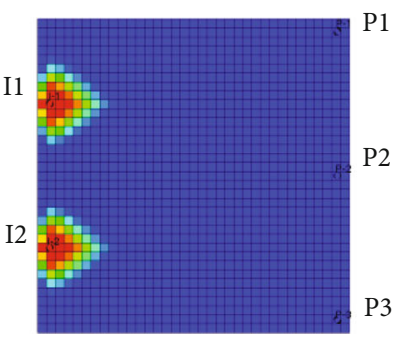

$T=\mathrm{t} 2$

(a) Low-permeability layer

I1

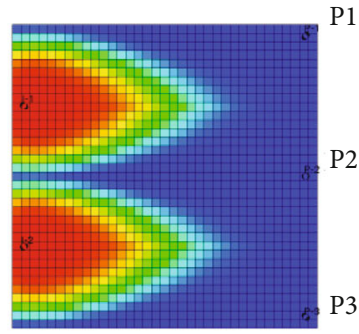

$T=\mathrm{t} 2$

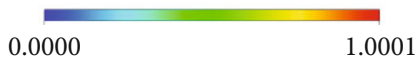

1.0001

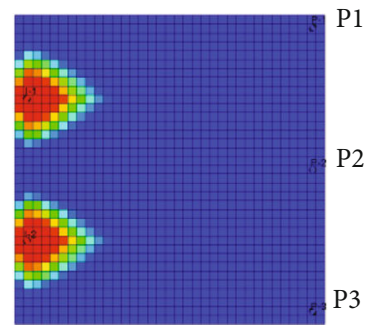

$T=\mathrm{t} 3$

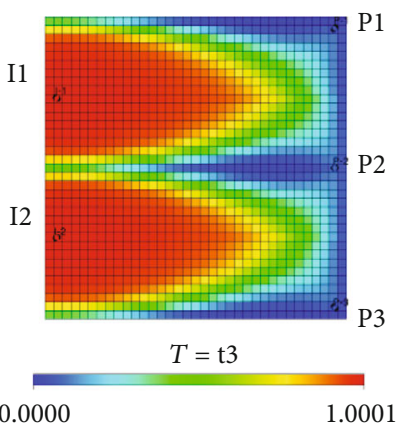

(b) High-permeability layer

producing degree of low-permeability layer, but injected water in high-permeability layer will compress polymer displacement area.

\subsubsection{Production Characteristics}

(1) Field. Figures 7 and 8 show the water cut and cumulative oil production of field in different schemes, and the pure polymer flooding case has the largest reduction of water cut and the highest cumulative oil production, even though the total injection amount is relatively small; the water cut reduction of the water-polymer coflooding case is small, and the cumulative oil production is less than that of pure polymer flooding. Comprehensive comparison results show that for field, pure polymer flooding has the best effect of water cut reduction and oil production acceleration, and waterpolymer coflooding will affect the overall development of the oilfield.

(2) Wells. Figure 9 shows the cumulative oil production of three production wells in different schemes. It can be seen that cumulative oil production of well P1 corresponding to the polymer injector in water-polymer coflooding is higher than that of pure polymer flooding. This is because the polymer solution in high permeability layer presents a slow advancing speed, as shown in Figures 5 and 6, and part of injected water has a certain inclination effect towards well $\mathrm{P} 1$, which provides sufficient energy for this well and forms a synergy effect. For well P2 and well P3, pure polymer flooding case shows a better oil increasing than water-polymer 

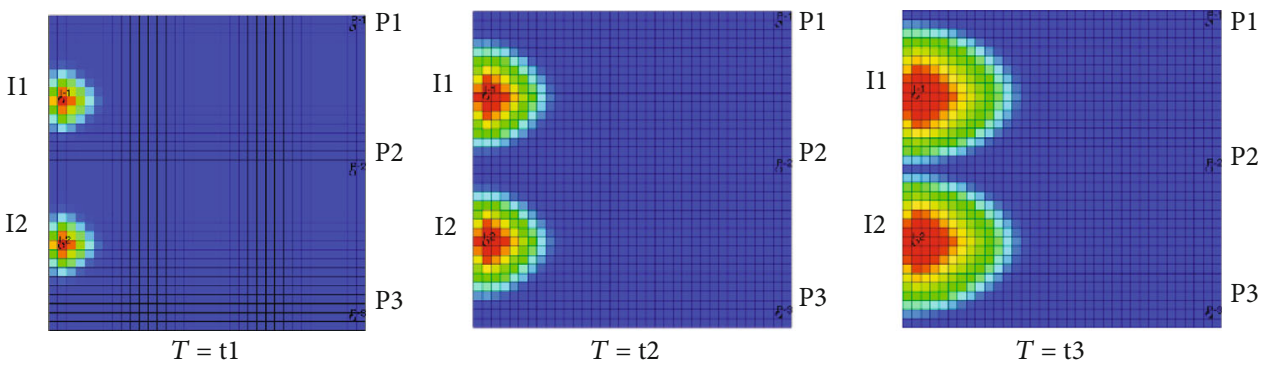

(a) Low-permeability layer
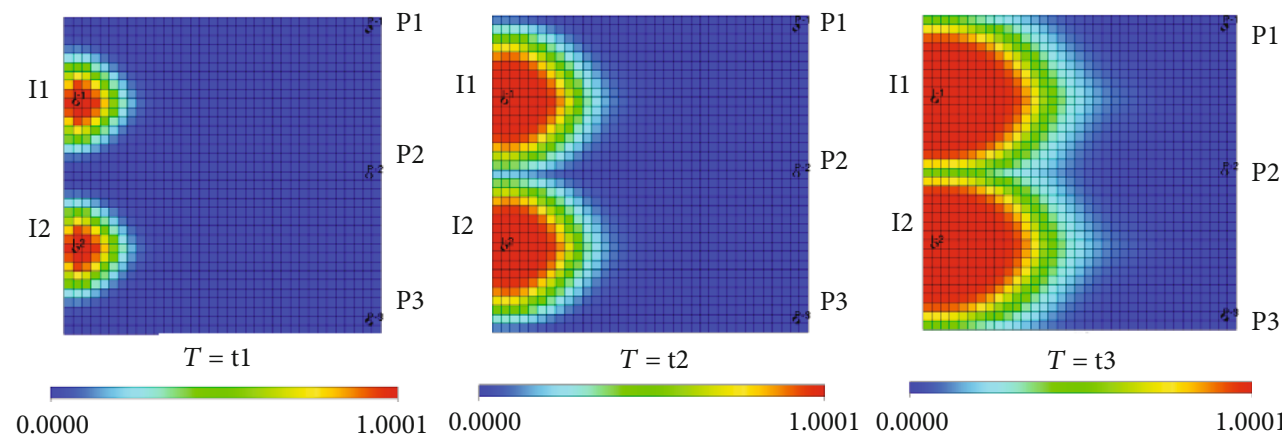

(b) High-permeability layer

FIGURE 5: Distribution of injected fluid at different time in pure polymer flooding.
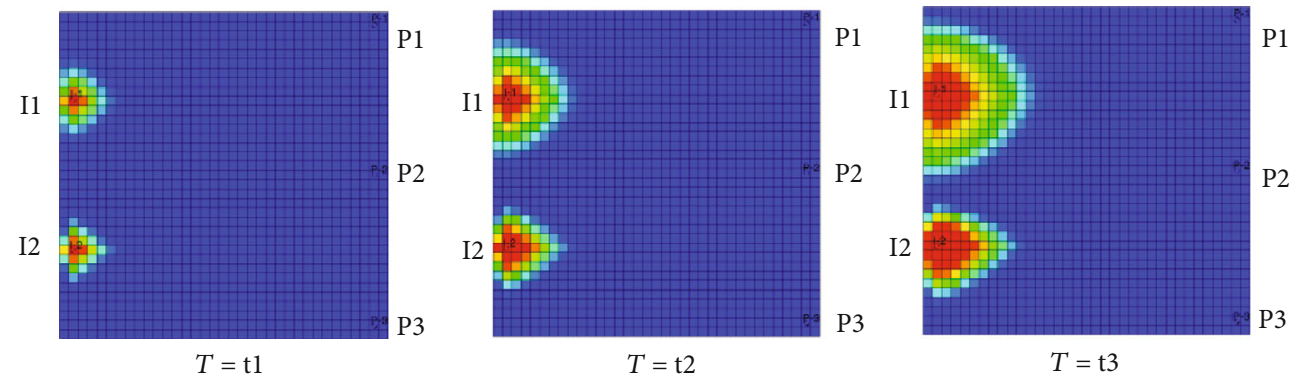

(a) Low-permeability layer
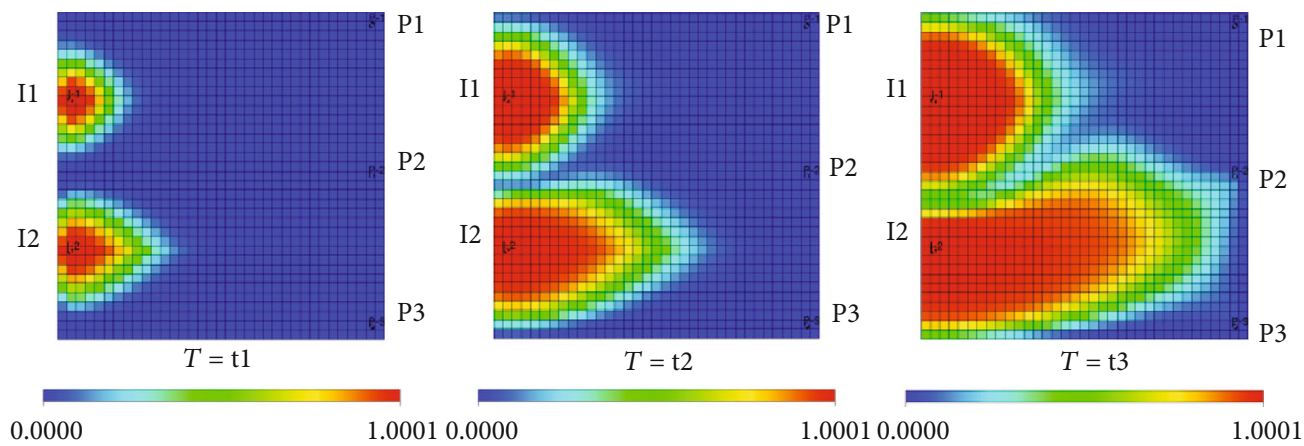

(b) High-permeability layer

FIGURE 6: Distribution of injected fluid at different time in water-polymer coflooding. 


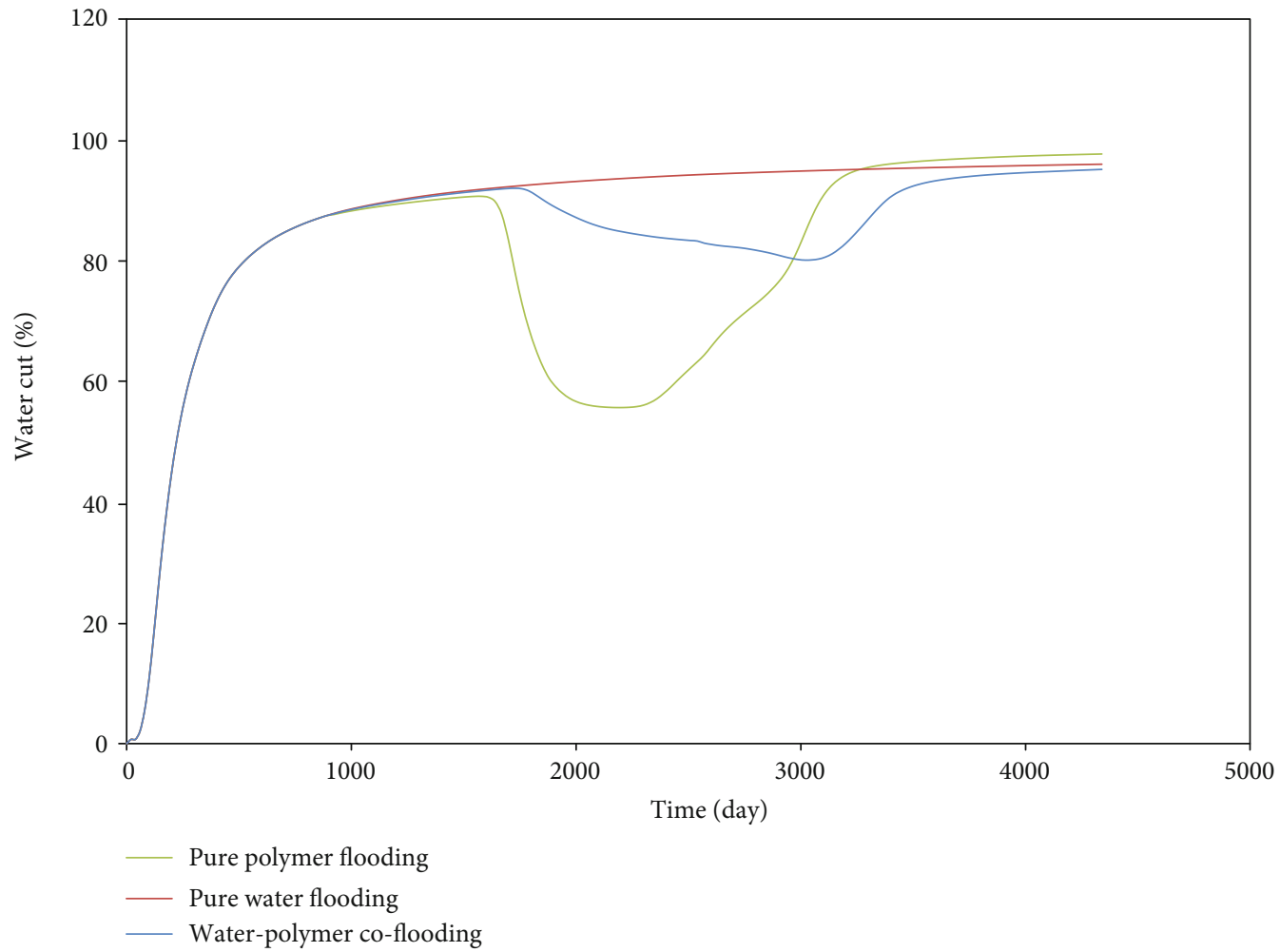

Figure 7: Water cut in different schemes.

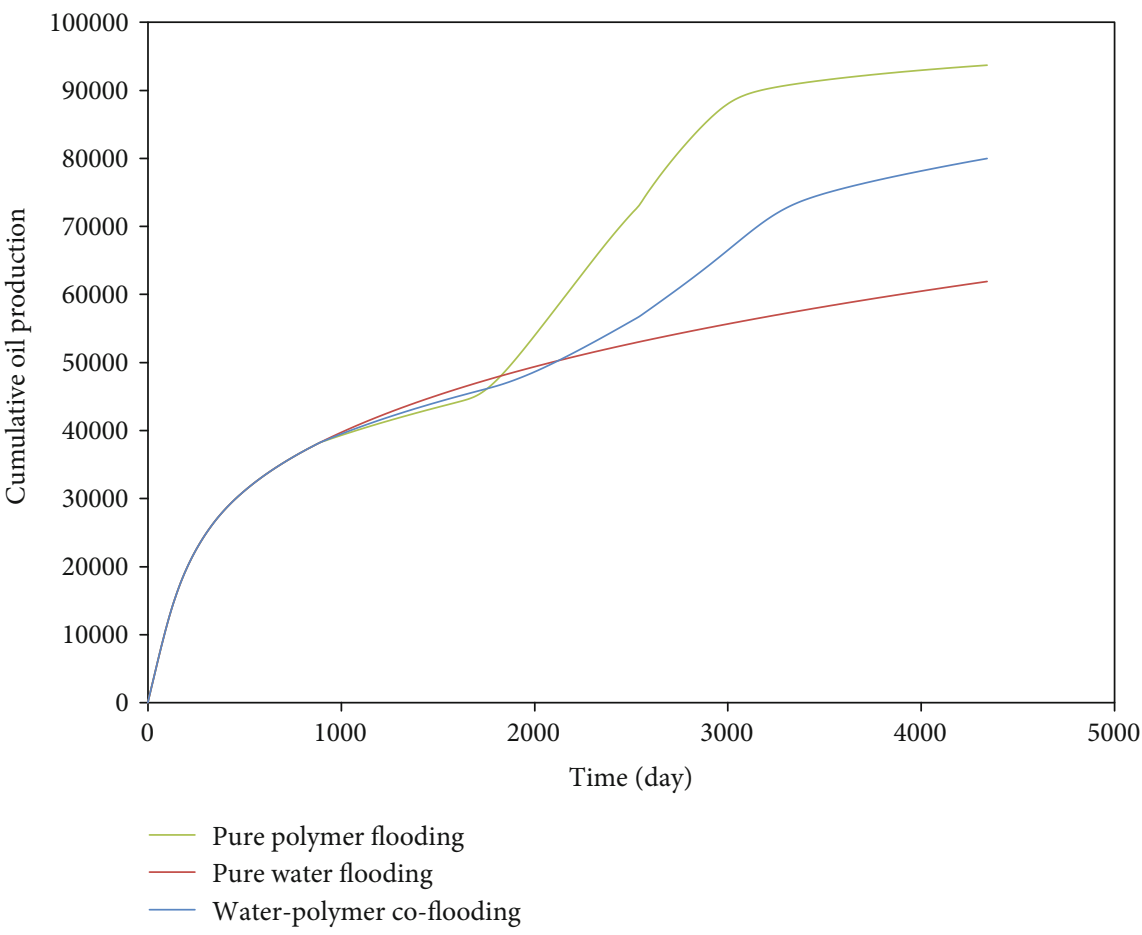

FIGURE 8: Cumulative oil production in different schemes.

coflooding and pure water flooding, especially for well P3, water-polymer coflooding nearly has no effect on oil increasing compared with pure water flooding.
Figure 10 shows the water cut of three production wells in different schemes. It can be seen that well P1 has a drastic water cut reduction in water-polymer coflooding 


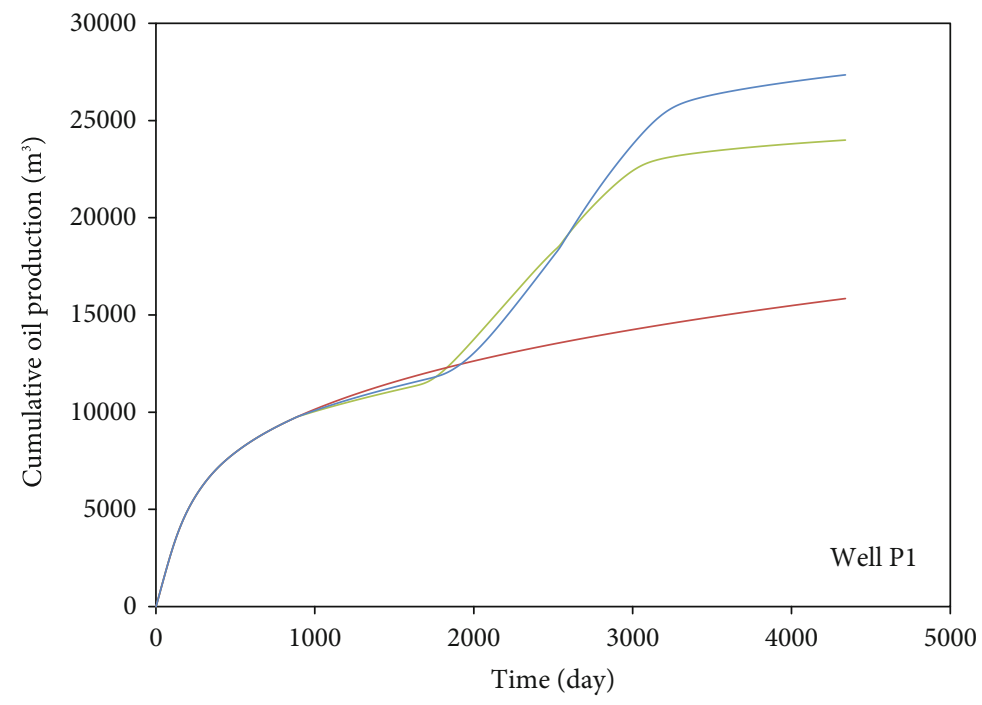

- Pure polymer flooding

- Pure water flooding

— Water-polymer co-flooding

(a) Cumulative oil production of well P1

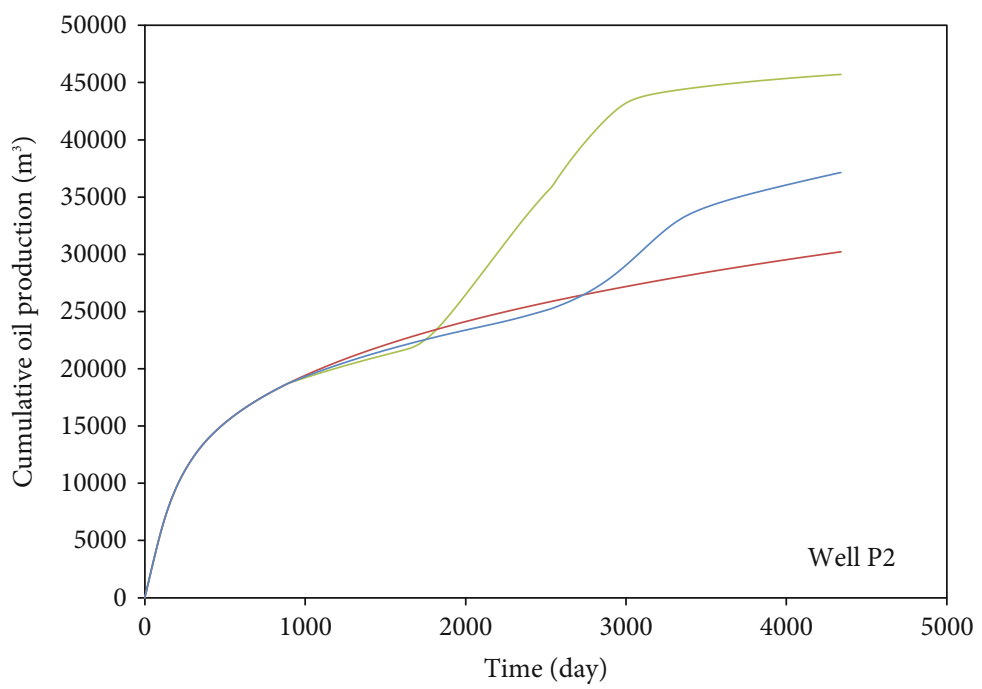

_ Pure polymer flooding

_ Pure water flooding

_ Water-polymer co-flooding

(b) Cumulative oil production of well P2

Figure 9: Continued. 


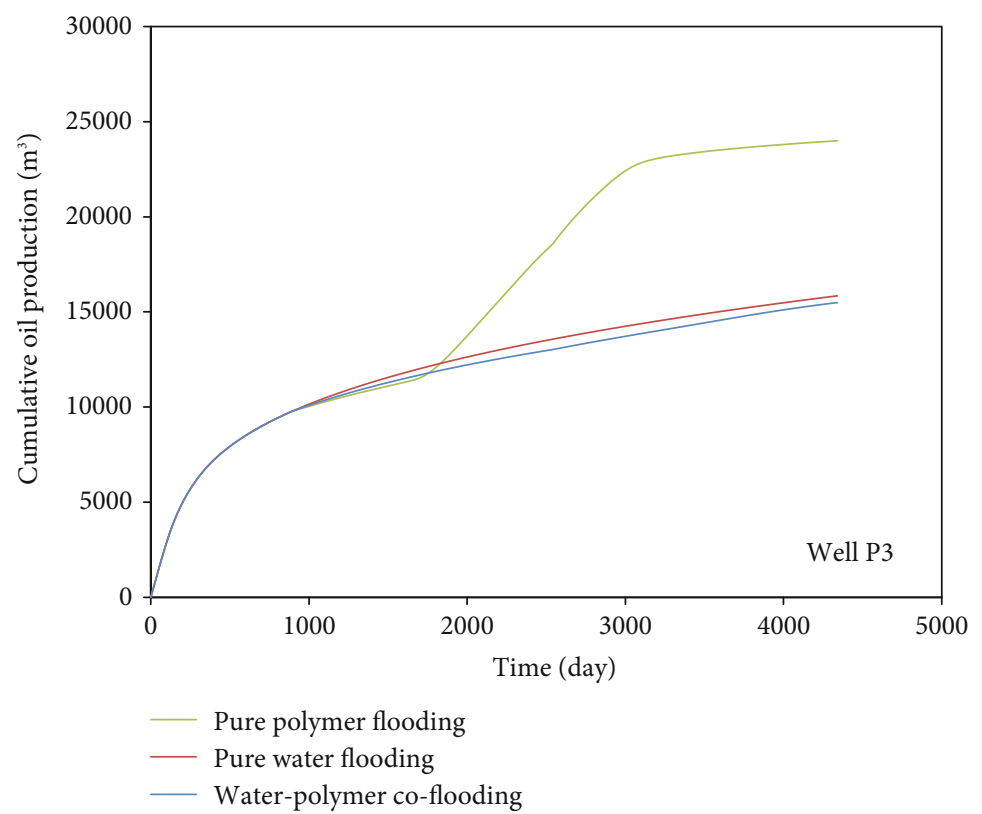

(c) Cumulative oil production of well P3

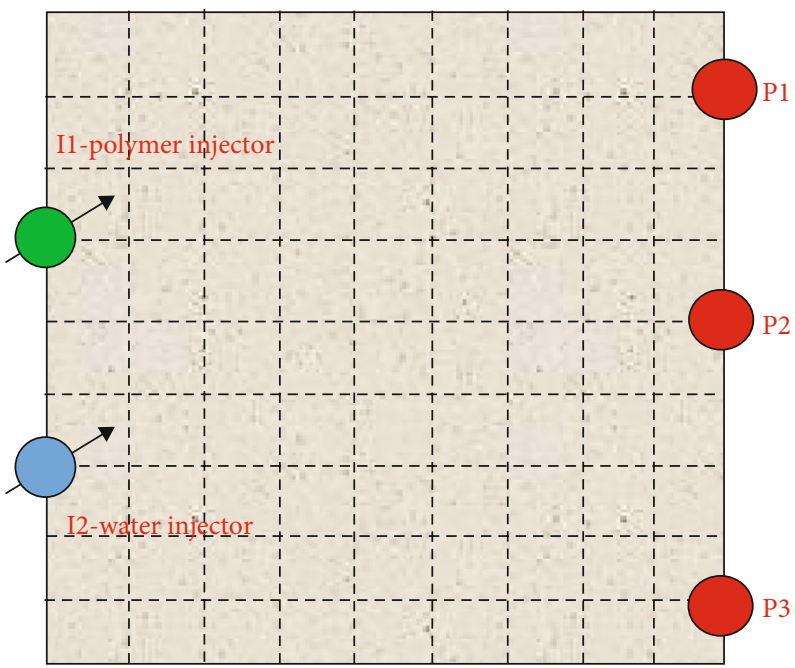

(d) Distribution of wells

Figure 9: Cumulative oil production of wells in different schemes.

and pure polymer flooding, and the water breakthrough is later in water-polymer coflooding, which is brought by the larger injection rate of water injector, and more oil is displaced toward well P1. The water cut reductions in waterpolymer coflooding of wells P2 and P3 are not obvious, because injected water advances and breaks through at producers quickly.

\subsection{Analysis of Water-Polymer Perturbation Coefficient}

3.3.1. Perturbation Coefficient $\tau$ and Oil Increment. In order to better characterize the variation laws of water-polymer perturbation coefficient at the second stage, the time of water-polymer coflooding is extended. Figures 11 and 12 show the $\tau$ and interval-oil-increment (interval-oil-increment: the oil production of water-polymer coflooding minus that of pure polymer flooding), respectively. At the early stage, $\tau>0$, which means that the positive effect plays a major role, and the displacement volume of waterpolymer coflooding is larger. At the following stage, $\tau<0$, and the negative effect brought by the decrease of polymer displacement volume gradually appears, and the oil increasing of water-polymer coflooding is inferior to that of pure polymer flooding. In general, results show that the oil increasing of pure polymer flooding is much higher than that of coflooding, and $\tau$ also corresponds to the interval-oil-increment. Furthermore, it also proves the feasibility of using $\tau$ and $\tau_{c}$ to characterize the development effect of water-polymer coflooding.

3.3.2. Stage Division. As shown in Figures 11 and 12, by comparing the process of water-polymer coflooding with pure 


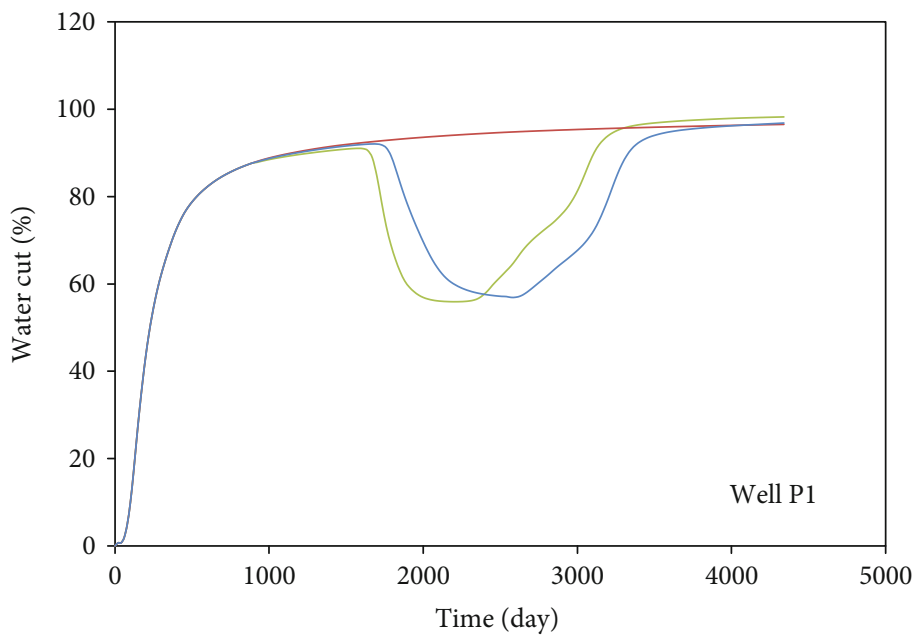

_ Pure polymer flooding

Pure water flooding

Water-polymer co-flooding

(a) Water cut of well P1

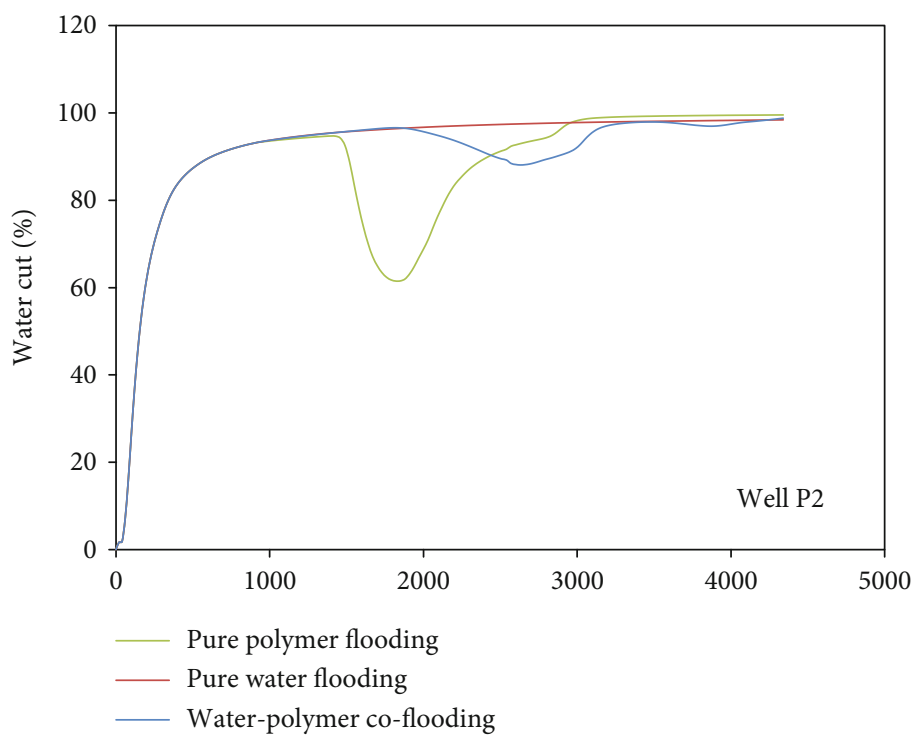

(b) Water cut of well P2

Figure 10: Continued. 


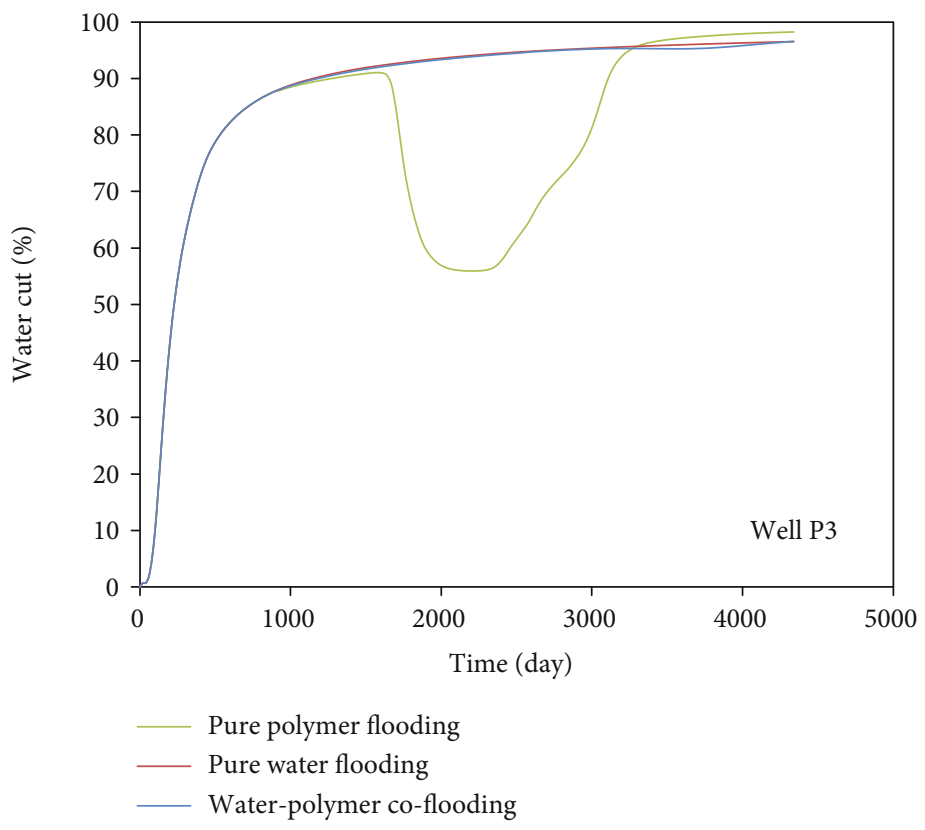

(c) Water cut of well P3

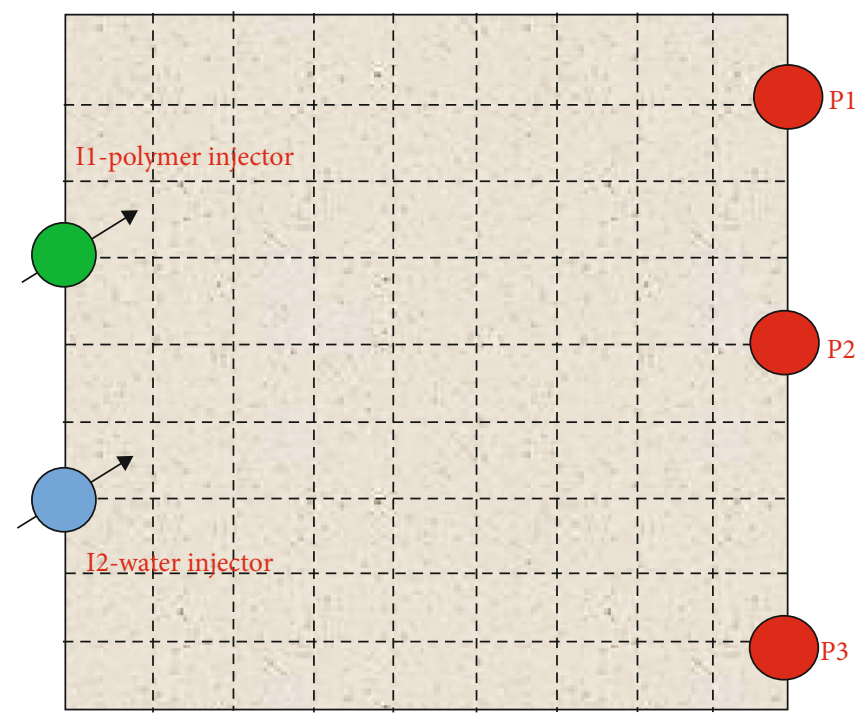

(d) Distribution of wells

FIGURE 10: Water cut of wells in different schemes.

polymer flooding, the variation laws of $\tau$ and $\tau_{c}$, interval-oilincrement, and cumulative-oil-increment are analyzed, and accordingly, water-polymer coflooding process can be divided into five stages:

(1) $\tau=A$ ( $A>0$, constant). Due to the higher injection rate of water, the displacement volume of waterpolymer coflooding is larger before injected water breaks through at producers. Combined with the interval-oil-increment curve, the oil increasing effect of coflooding at this stage is larger than that of pure polymer flooding.

(2) $\tau=A \rightarrow \tau=0$. Breakthrough point in Figure 11 means the injected water breakthrough at producers occurs. At this stage, the effect of coflooding is still better than that of pure polymer flooding, but the positive effect gradually decreases due to the rapid fingering of injected water, leading to the decrease of displacement volume of injected water. As $\tau=0$, the corresponding point can be defined as coordination point, at which the displacement volume of water-polymer coflooding and pure polymer flooding is the same.

(3) $\tau=0 \rightarrow \tau=\tau_{\min } . \tau$ decreases rapidly from zero, which indicates that the perturbation degree gradually increases, and the difference of displacement volume between water-polymer coflooding and pure polymer flooding reaches the maximum as $\tau=\tau_{\text {min }}$. 


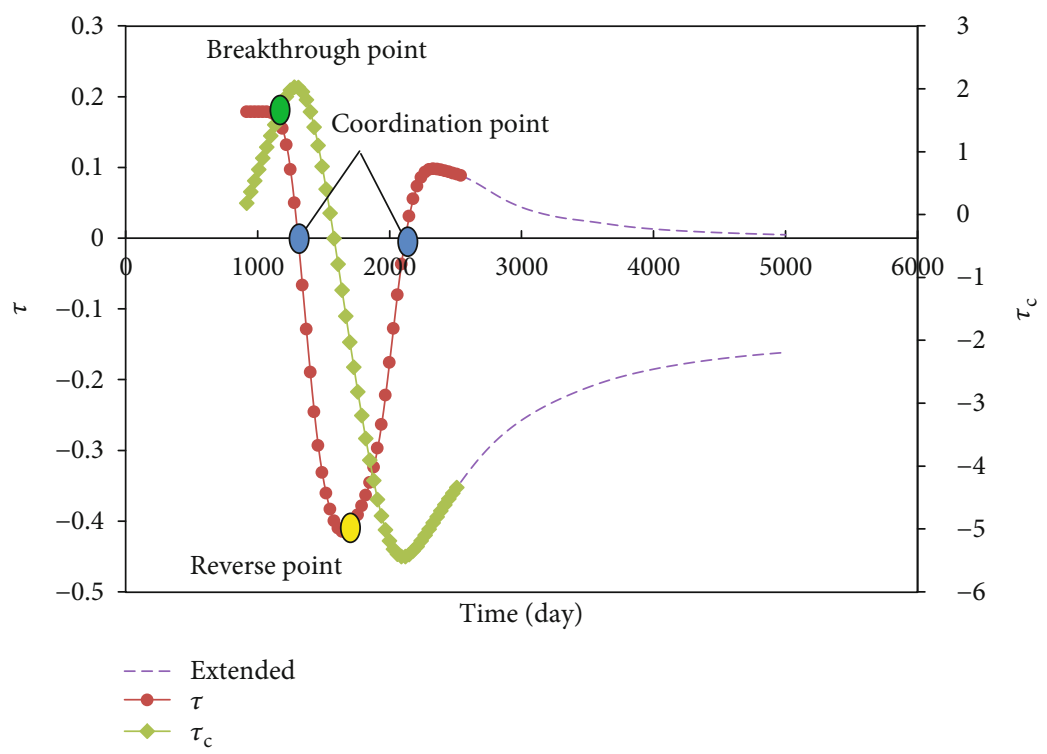

FIGURE 11: Water-polymer perturbation coefficient.

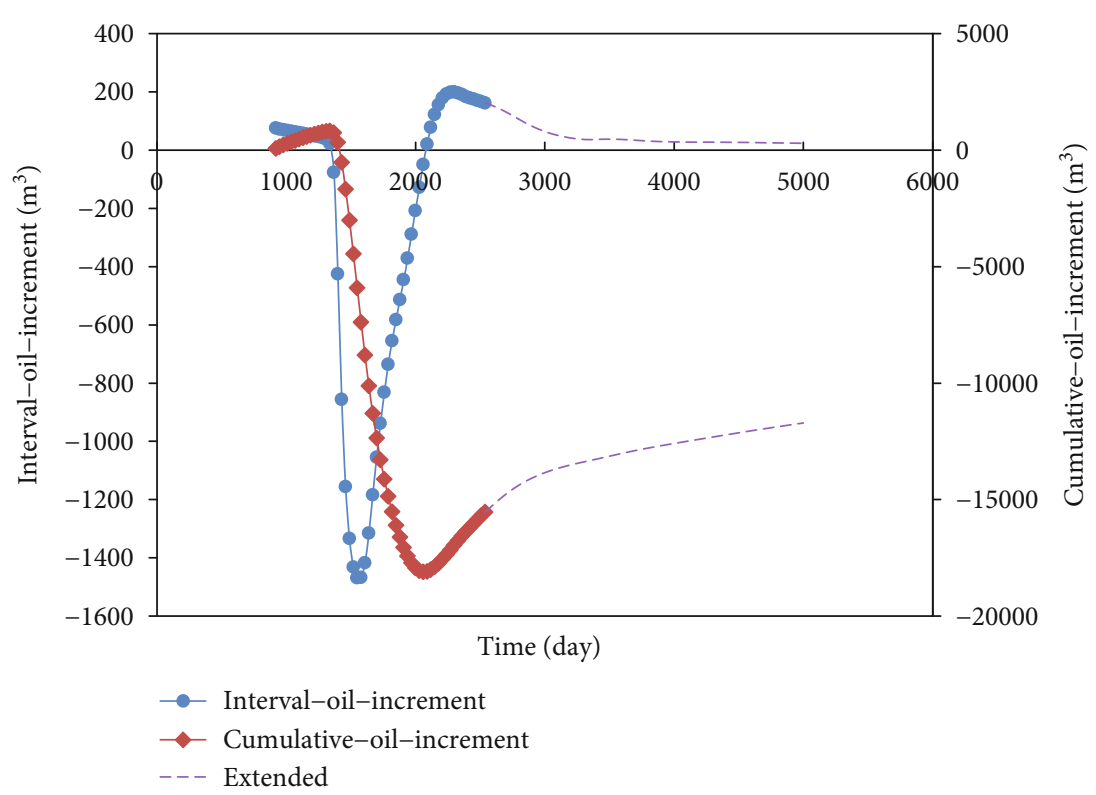

Figure 12: Comparison of oil increment.

(4) $\tau=\tau_{\min } \rightarrow \tau=0 . \tau$ increases from the lowest point, which is due to the decrease of oil-producing potential in pure polymer flooding; however, the overall oil increasing effect is still better than that of coflooding. Continuing until another coordination point is reached, the displacement volume of water-polymer coflooding and pure polymer flooding becomes the same.

(5) $\tau \rightarrow 0$. After a long time of development, the displacement volume and cumulative oil production of coflooding and pure polymer flooding have basically remained unchanged and reached equilibrium.

\section{Controlling Strategy}

In water-polymer coflooding process, water breakthrough at producers occurs more quickly than polymer solution due to the stronger injectivity, and injected water will also interfere the displacement front of polymer solution. In order to achieve a balanced displacement and reduce viscous fingering, alternative injection is adopted to improve development effect [18-23]. In this study, three simulation schemes are set up with the same injection amount of water and polymer but different alternating cycles.

Case one: without alternation.

Case two: two alternating cycles. 


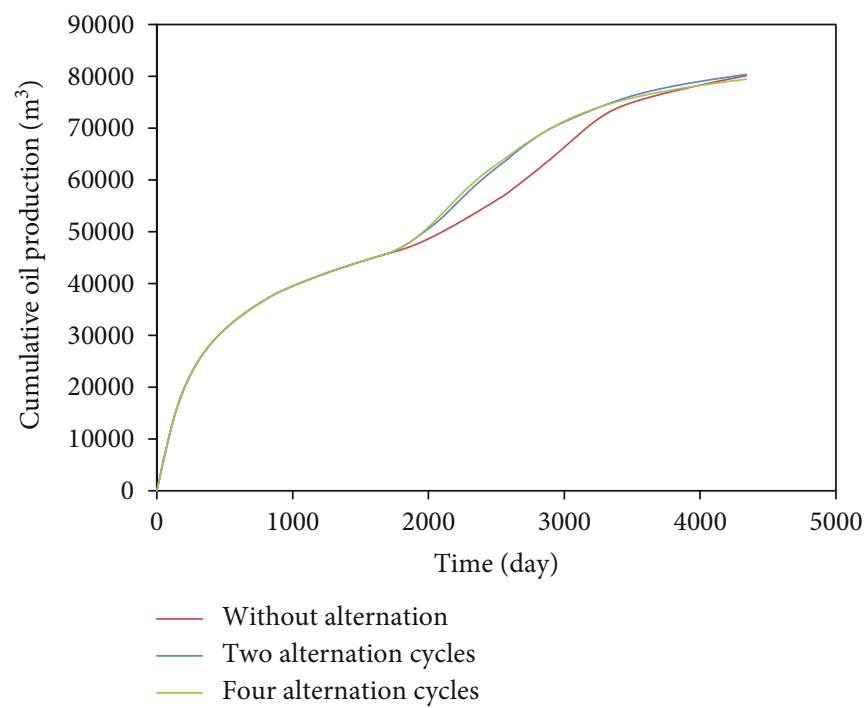

FIGURE 13: Cumulative oil production in different schemes.

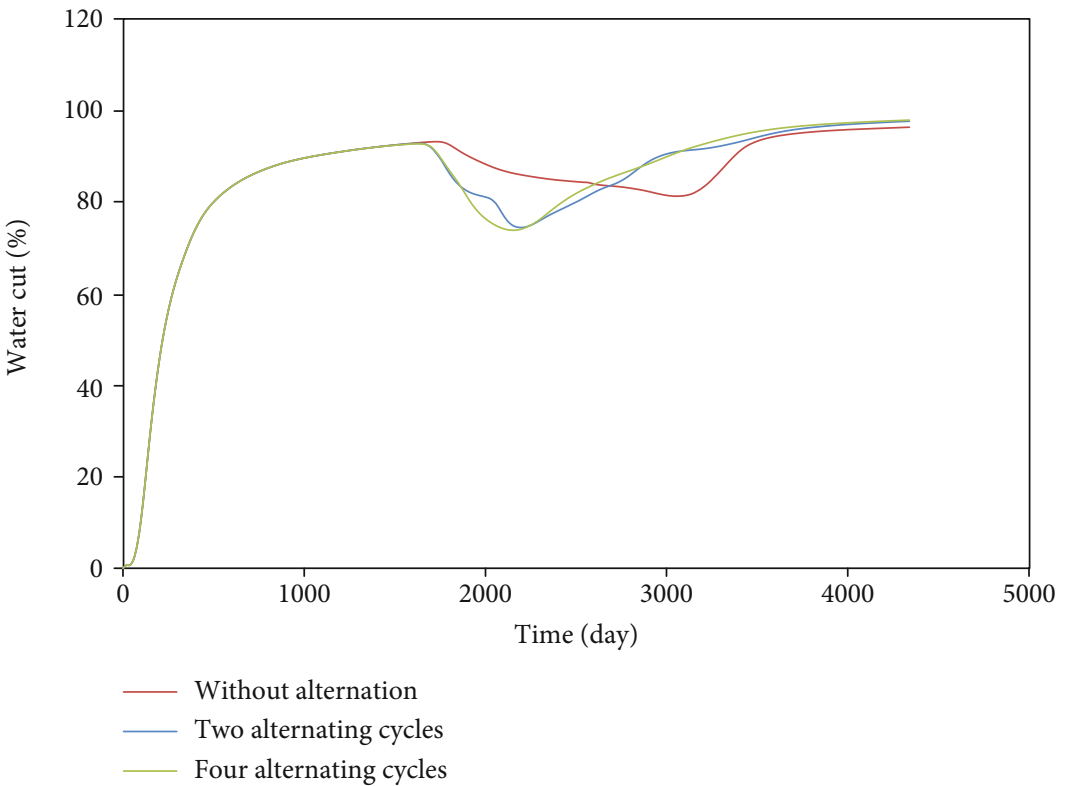

Figure 14: Water cut in different schemes.

Case three: four alternating cycles.

It can be seen from Figures 13 and 14 that under the same polymer dosage, the cumulative oil production and water cut are significantly increased and decreased, respectively, by water-polymer alternative injection compared with case one. The cumulative oil production increases with the increase of alternating cycles, but with small range. It can be seen that the influence of injected water to polymer can be significantly reduced, and the development effect can be improved by alternative injection.

Figure 15 shows the changes of $\tau$ with and without alternative injection. As can be seen, $\tau$ presents a slower descending rate as alternating cycles increase, which means that by conducting alternative injection, the displacement front edge tends to become uniform; thus, the injection fluid penetra- tion in continuous injection mode can be restrained, and the breakthrough time of injected liquid can be delayed.

\section{Field Application}

JZ oilfield is a high permeability and multilayer reservoir located at Bohai Bay. Oil production from this field started in 1995, and polymer injection began in 2007, at which point water cut is about $80 \%$, and following extraordinary production acceleration and water cut reduction were observed, as shown in Figure 16. In order to better utilize the remaining reserves, infill wells were drilled in polymer injection area in 2016, and the new infill wells injected water instead of polymer solution in order to maintain injection capacity, causing water injectors and polymer injectors coexist at this area. 


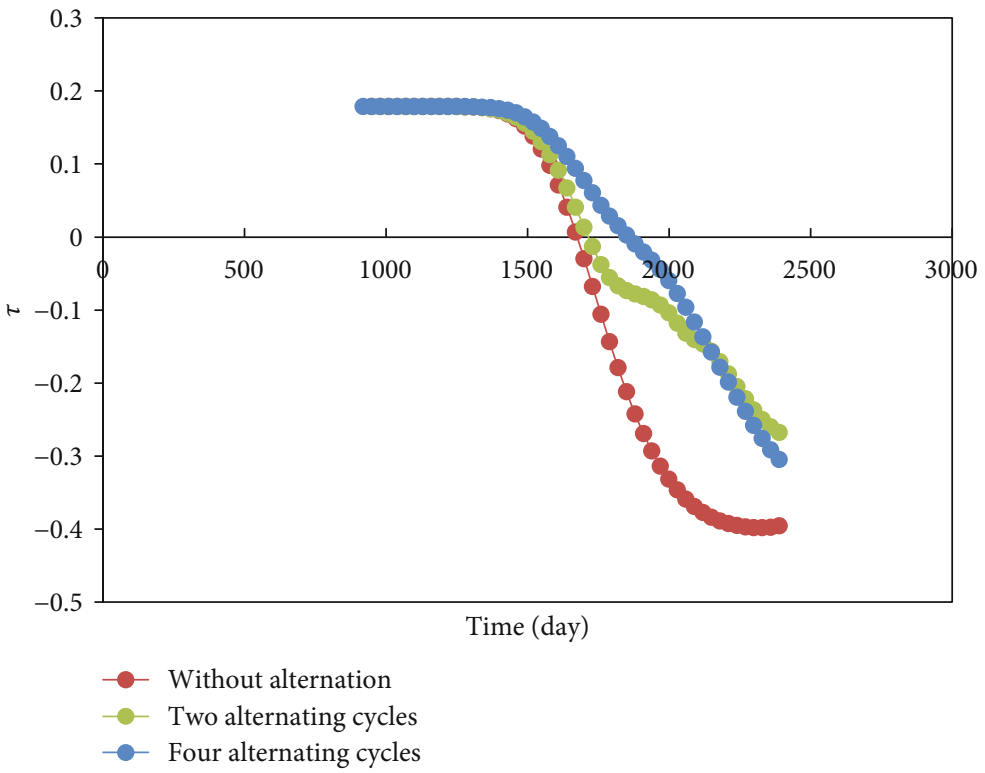

FIGURE 15: Water-polymer perturbation coefficient with different alternating cycles.



FIGURE 16: Production history of JZ oilfield. 


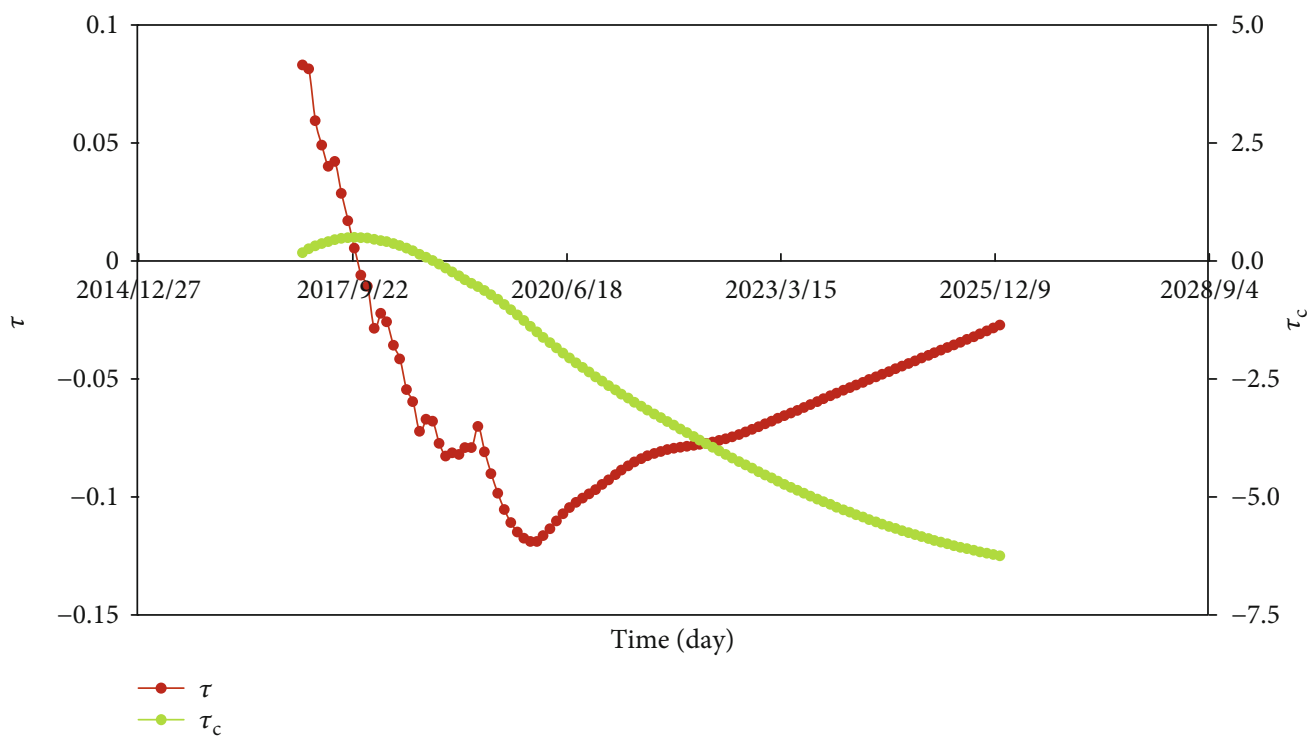

FIGURE 17: Change of water-polymer perturbation coefficient.

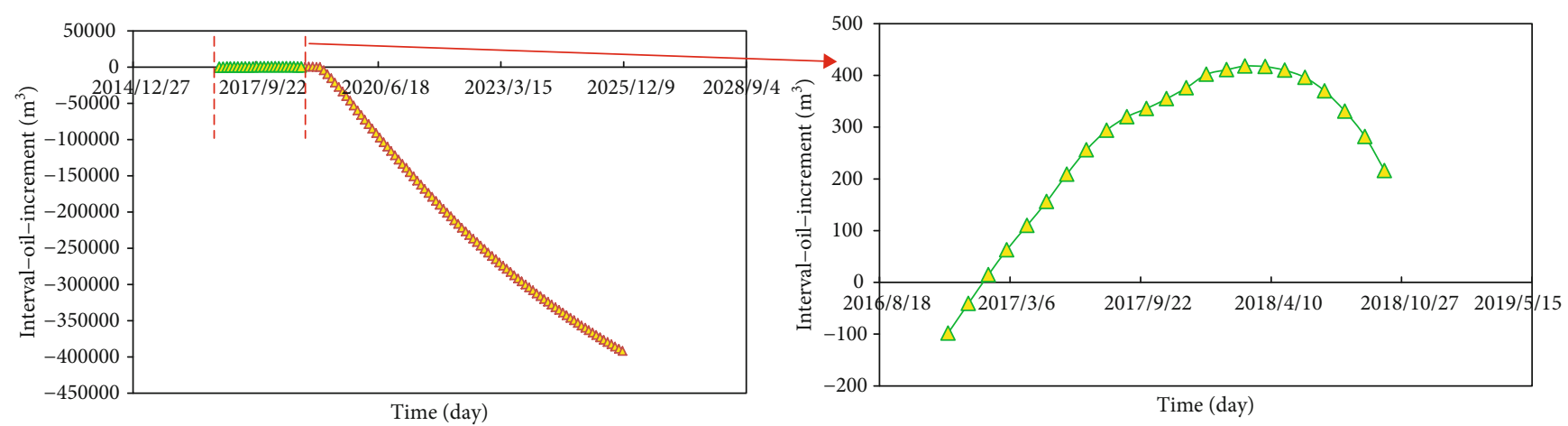

FIGURE 18: Change of interval-oil-increment.

Eq. (3) and Eq. (4) are adopted to evaluate the waterpolymer perturbation degree; as shown in Figures 17 and 18 , there is a good correspondence of $\tau$ between the field case and the mechanism model. At the early stage $(\tau>0)$, waterpolymer coflooding has a larger displacement volume and better oil production, even though the oil increasing is pretty small compared with polymer flooding (Figure 18). Then $\tau$ decreases rapidly, showing that injected water breaks through at producers, and polymer flooding manifests a more advantageous oil increasing.

\section{Conclusion}

Aiming at the problem of water-polymer coflooding in offshore oilfields, a new method to quantitatively characterize waterpolymer perturbation is proposed and its relation to production is analyzed, and the following conclusions are drawn:

(1) Based on the analysis of water-polymer perturbation process, the water-polymer perturbation coefficient considering the dynamic change of displacement volume of injected water and polymer is established, which can reflect the process of water-polymer perturbation and quantitatively characterize waterpolymer perturbation degree

(2) The perturbation rules and production characteristics of water-polymer coflooding, pure water flooding, and pure polymer flooding are studied. Waterpolymer coflooding displays a larger displacement volume before the breakthrough of injected water, manifesting with more oil being displaced, but the duration is very short. In general, pure polymer flooding presents a better oil increasing

(3) Process of water-polymer coflooding can be divided into five stages. Perturbation coefficient has a good correspondence with the oil increment, which can characterize the stage of water-polymer coflooding. The development effect can be significantly improved by water and polymer alternative injection according to simulation study

(4) Field application shows that the perturbation coefficient can reflect the characteristics of water-polymer 
coflooding, which is convenient for the formulation of adjustment measures and the optimization of schemes

\section{Nomenclature}

$\Delta \sum m_{P}:$ Polymer dosage in water-polymer coflooding $(\mathrm{kg})$

$\Delta \sum D_{w}$ : Interval increase of water displacement volume $\left(\mathrm{m}^{3}\right)$

$\Delta \sum D_{p}$ : Interval decrease of polymer displacement volume $\left(\mathrm{m}^{3}\right)$

$\Delta A^{\prime}: \quad$ Interval change of single-well displacement area in pure polymer flooding $\left(\mathrm{m}^{2}\right)$

$\triangle A$ : Interval change of polymer displacement area in water-polymer coflooding $\left(\mathrm{m}^{2}\right)$

$\Delta B: \quad$ Interval change of water displacement area in waterpolymer coflooding $\left(\mathrm{m}^{2}\right)$

$d: \quad$ Reservoir thickness (m).

\section{Data Availability}

The data used to support the findings of this study are included within the article.

\section{Conflicts of Interest}

The authors declare that they have no conflicts of interest.

\section{Acknowledgments}

The authors are grateful for financial support from the National Science and Technology Major Project of China (Grant No. 2016ZX05025-003) and CNOOC Key Research Program (Grant No. CNOOC-KJ135ZDXM36TJ02ZY).

\section{References}

[1] Y. C. Su and T. L. Li, "Practice of development adjustment in offshore sandstone oilfield in high water cut stage," China Offshore Oil and Gas, vol. 28, no. 3, pp. 83-90, 2016.

[2] Y. Y. Liu, X. D. Kang, Z. J. Wei, J. L. Hao, and J. Zhang, "Permeability contrast of offshore layered unconsolidated sandstone reservoir," Fault-Block Oil \& Gas Field, vol. 25, no. 5, pp. 622-625, 2018.

[3] G. Z. Liao, Q. Wang, H. Z. Wang, W. D. Liu, and Z. M. Wang, "Chemical flooding development status and prospect," Acta Petrolei Sinica, vol. 38, no. 2, pp. 196-207, 2017.

[4] S. Yuan and Q. Wang, "New progress and prospect of oilfields development technologies in China," Petroleum Exploration and Development, vol. 45, no. 4, pp. 698-711, 2018.

[5] L. Sun, X. Wu, W. Zhou, X. Li, and P. Han, “Technologies of enhancing oil recovery by chemical flooding in Daqing Oilfield, NE China," Petroleum Exploration and Development, vol. 45, no. 4, pp. 673-684, 2018.

[6] F. J. Zhang, W. Jiang, F. J. Sun, and S. W. Zhou, "Key technology research and field test of offshore polymer flooding," Strategic Study of CAE, vol. 13, no. 5, pp. 31-33, 2011.

[7] X. S. Zhang, H. J. Wang, E. G. Tang, and S. S. Jiang, "Research on reservoir potential and polymer flooding feasibility for EOR technology in Bohai offshore oilfield," Petroleum Geology and Recovery Efficiency, vol. 16, no. 5, pp. 56-59, 2009.
[8] X. D. Kang and J. Zhang, "Offshore heavy oil polymer flooding test in JZW area," in SPE165473 presented at the SPE Heavy Oil Conference, Society of Petroleum Engineers, Calgary, Alberta, Canada, June 2013.

[9] B. Z. Li, X. D. Kang, J. Zhang, E. G. Tang, and J. R. Yang, "The water and polymer interaction and control methods after well pattern infilling in polymer flooding region," Science Technology and Engineering, vol. 19, no. 17, pp. 168-172, 2019.

[10] G. Yang, R. Z. Jiang, X. L. Li, and Y. Jiang, "Evaluation of polymer flooding performance using water-polymer interference factor for an offshore oil field in Bohai Gulf: a case study," in SPE190253 presented at the SPE Improved Oil Recovery Conference, Society of Petroleum Engineers, Tulsa, Oklahoma, USA, April 2018.

[11] B. Y. Shao, W. Zhang, L. Y. Shi, and Y. L. Yin, "Development effect of water and polymer flooding in Daqing Saertu oilfield," Contemporary Chemical Industry, vol. 45, no. 7, pp. 16281630, 2016.

[12] G. Wang, B. Liu, X. R. Wang, G. H. Zhang, and W. Zhang, "Influencing factors analysis and field test of water and polymer interference in offshore oilfields," Petroleum Geology and Engineering, vol. 34, no. 1, pp. 91-95, 2020.

[13] G. Alusta, E. Mackay, J. Fennema, K. Armih, and I. Collins, "EOR vs. infill well drilling: field application of new decision making technique," in SPE163298-MS presented at the SPE Kuwait International Petroleum Conference and Exhibition, Society of Petroleum Engineers, Kuwait City, Kuwait, December 2011.

[14] J. C. Sun, Study on Dynamic Change Characteristics of TwoFlood Pressure System in Three-Stage Oil Production, Northeast Petroleum University, 2017.

[15] C. B. He, G. Z. Feng, X. Q. Xie, W. S. Zhao, and Y. Q. Li, "Study on physical simulation experiment of simultaneous water flooding and polymer flooding with multilayer heterogeneity model," Science Technology and Engineering, vol. 14, no. 7, pp. 160-163, 2014.

[16] J. Y. Dong, "Research on the contact zone between water flooding and polymer flooding in class II reservoirs with large-scale physical simulation model," Journal of Yangtze University (Natural Science Edition), vol. 16, no. 1, pp. 4449, 2019.

[17] W. T. Guan, "Study on the feasibility of simultaneous water flooding and polymer flooding in class II reservoir in Daqing oilfield," Petroleum Geology \& Oilfield Development in Daqing, vol. 4, pp. 106-108, 2008.

[18] Z. J. Wei, X. D. Kang, Z. Sun, and Y. Y. Liu, "Mechanism and influence factors of polymer flooding profile inversion in offshore heavy oil reservoirs," Journal of Xi'an Shiyou University (Natural Science Edition), vol. 33, no. 5, pp. 57-63, 2018.

[19] A. H. Abbas, D. S. Abdullah, M. Z. Jaafar, and A. Agi, "Comparative numerical study for polymer alternating gas (PAG) flooding in high permeability condition," SN Applied Sciences, vol. 2, no. 5, 2020.

[20] S. Majidaie, A. Khanifar, M. Onur, and M. Tan, "A simulation study of chemically enhanced water alternating gas (CWAG) injection," in SPE154152-MS presented at the SPE EOR Conference at Oil and Gas West Asia, Society of Petroleum Engineers, Muscat, Oman, April 2012.

[21] Z. J. Wei, X. D. Kang, J. Zhang, Y. Y. Liu, and Y. Zeng, "Unstable polymer flooding and its application in offshore heavy-oil field of China," in Presented at the Proceedings of the 
International Petroleum and Petrochemical Technology Conference, pp. 14-25, Beijing, China, 2020.

[22] P. H. Han, H. B. Liu, X. Han, R. B. Cao, Y. W. Zhang, and X. Y. Liu, "Alternative injection and its seepage mechanism of polymer flooding in heterogeneous reservoirs," in SPE174586-MS presented at the SPE Asia Pacific Enhanced Oil Recovery Conference, Society of Petroleum Engineers, Kuala Lumpur, Malaysia, August 2015.

[23] C. L. Dai, Q. You, X. Q. Fan et al., "Study and application of anionic and cationic polymers alternative injection for indepth profile control in low permeability sandstone reservoir," in SPE143458-MS presented at the SPE EUROPEC/EAGE Annual Conference and Exhibition, Society of Petroleum Engineers, Vienna, Austria, May 2011. 